Serra Cristobal, Rosario, La seguridad como amenaza. Los desafios de la lucha contra el terrorismo para el Estado democrático, Tirant lo Blanch. Valencia, 2020, 265 pp. ISBN 978-841336-666-1.

\author{
http://dx.doi.org/10.18543/ed-68(2)-2020pp377-383
}

1.- El libro que acaba de publicar la profesora SERRA es de los que pueden inducir a confusión por su título sugerente, aunque he de decir que una obra de Galbraith que escogí por entender mal el título es una de las que más influencia han tenido en mis reflexiones posteriores. No es la autora la que yerra en el título, que responde perfectamente al desarrollo de sus capítulos, sino las circunstancias sobrevenidas no solo en nuestro país sino en el mundo entero las que nos hacen caer en el error de creer que vamos a reflexionar sobre la presente (y por ello apremiante) situación de pandemia aunque, sin embargo, la autora aclara perfectamente en el subtítulo que va a centrarse en la lucha antiterrorista y, en especial, en la yijadista.

Ello no obstante, es tal la gravedad de la realidad actual y su relación con el tema desarrollado (en realidad, no tanto con el tema sino con el fondo doctrinal que subyace al mismo) que a lo largo de la lectura persiste (acuciándonos en cierta forma) esa impresión de que nos falta algo. Pero, insisto, no porque falle el enfoque de la autora sino porque todas las medidas que se estudian como extraordinarias y excepcionales en el caso de la lucha antiterrorista nos recuerdan, y mucho, a las que estamos viviendo en la actualidad, con el agravante de no tener un enemigo externo al que derribar y de que las medidas excepcionales no se adoptan sobre sospechosos sino sobre toda la ciudadanía. Porque, en definitiva, la cuestión no es tan solo la de garantizar dentro de lo posible la seguridad ciudadana, sino la de analizar cómo se cumple tal propósito sin que se vean afectados los más consolidados derechos de la persona que han venido caracterizando la evolución y consolidación de las democracias más avanzadas.

Pero sea lo que deducimos de la lectura del libro, sea la observación de la realidad que actualmente vivimos, resulta bastante imposible negar la afectación de tales derechos, por lo que la cuestión se traslada a la que de algún modo resume el título: el bien público seguridad puede convertirse en amenaza; así, aceptada la necesidad de su defensa y siendo los derechos fundamentales y los valores constitucionales constitutivos 
esenciales de la forma democrática del Estado, la cuestión exigirá profundizar en las condiciones y parámetros que se habrán de tener en cuenta a la hora de verse obligados los poderes públicos a restringir el libre ejercicio de los derechos como precio ineludible a la hora de garantizar o procurar la mayor seguridad posible.

Aun cuando la autora no entra en su desarrollo (ni tendría por qué hacerlo) si late en el fondo de la principal cuestión la determinación de la funcionalidad que en el sistema general de derechos constitucionales asume la seguridad, si tal es un derecho más, una condición previa y esencial de todos los derechos o, incluso, un limite al ejercicio de los mismos. Y en esta decisión crucial influye sin duda la concepción sistemática de los derechos fundamentales en cada ordenamiento (por lo que se refiere al nuestro me limito a recordar un breve trabajo como punto de partida para este tipo de análisis: SÁNCHEZ FERRIZ, R. Ordenación sistemática de los derechos y libertades del Título I de la Constitución, Constitución, estado de las autonomías y justicia constitucional : (libro homenaje al profesor Gurmesindo Trujillo), coord. por Luis Aguiar de Luque, Tirant, 2005) y, por supuesto la tradicional pertenencia a los dos grandes sistemas jurídicos, de common law y de civil law (esta es una de las bases con que trabaja una de las más conocidas especialistas en el tema aquí estudiado: A. VEDASCHI, Has the balancing of rights given way to a hierarchy of values?, 1 Comparative Law Review 2010) cuyas diferentes perspectivas podrían explicar algunas de las soluciones adoptadas frente a un mismo problema. La cuestión, como afirma esta autora es lograr funcionalizar la seguridad respecto de los derechos y no al revés pues «puede observarse que la búsqueda espasmódica de una jerarquía de valores muy a menudo acaba colocando la seguridad en el ápice».

Todo ello parece ser el fondo del que parte SERRA, que a lo largo de la obra manifiesta su preocupación por la frecuente afectación de tantos derechos como al estado democrático le ha costado consolidar como su propio fundamento. De ahí que, sea en la lucha antiterrorista, sea en la actual pandemia, se esté produciendo ciertos deslizamientos y desequilibrios entre los tres poderes y hasta se pongan en riesgo los fundamentos del constitucionalismo democrático ya puestos a prueba, por cierto, con la revolución tecnológica y sus efectos en tales fundamentos constitucionales (sobre tales efectos también llama la atención la autora reclamando garantías en la protección de nuestros datos personales incluso en los casos en que la finalidad perseguida sea garantizar la seguridad (p. 53).

2.- Comienza el estudio por situarnos en la terminología más usada en torno a la seguridad mostrándonos cómo cada acepción responde a un determinado enfoque o, incluso, al carácter solo nacional o transnacional, y hasta global, de esa seguridad que a todos preocupa; pero, sin perjuicio de las múltiples referencias al derecho extranjero acaba centrándose especialmente en la normativa europea a la que nos conduce a través de referencias tanto anglosajonas como continentales aun sin haber emprendido la 
eventual comparación y/o divergencia entre los dos grandes sistemas jurídicos.

En efecto, ya en el Capítulo 3 se centra en el aspecto transnacional del fenómeno terrorista y sus reacciones aprovechando la referencia a la directiva 2017/541 del Parlamento europeo y del Consejo para aclarar la diversidad de denominaciones de grupos y acciones terroristas que conforman un complejo mosaico de coincidencias y contradicciones de difícil comprensión para quien no se detiene en un análisis detallado como el que la autora realiza.

Un común denominador en tal complejidad de grupos terroristas, e incluso en las reacciones que los Estados han de emprender para combatirlos es su convivencia en la era digital con todas las posibilidades que la recopilación y manipulación de datos personales ofrece a los Estados pero, también, a los grupos terroristas que utilizan las redes como medio de comunicación y también de propaganda y de formación y estímulo ideológico, que permite mantener viva la ideología aun después del fracaso del DAESH. Y otro denominador de no menor consideración es la presencia de terroristas extranjeros, procedentes incluso de países democráticos europeos, que también han dado lugar a medidas de control en especial de los viajes aéreos auspiciadas tanto por la ONU como por la UE.

Al mencionar los tres grandes tipos de medidas que con carácter general se han adoptado por los estados democráticos subraya como país europeo con medidas más decididas a Francia (coincidiendo con VEDASCHI, À la guerre comme á la guerre. La disciplina della guerra nel diritto costituzionale comparato, Torino, Giappichelli, 2007); y en cambio España destaca como país en que formalmente apenas si ha habido medidas legislativas específicas aunque cabe creer que en la realidad se aplican medidas semejantes a los otros países; con todo, la situación normativa tiene cierta lógica porque España ya tenía la experiencia de la lucha contra el terrorismo interior hasta el punto de haber sido prevista la eventual suspensión de derechos en la propia Constitución.

La principal preocupación ante la adopción de medidas excepcionales por los países democráticos es la de que las mismas permanezcan convirtiéndose en cierto modo en derecho normalizado, cuestión que también ha adquirido extraordinaria actualidad en los meses en que estuvo vigente el estado de alarma entre nosotros. En página 96 lo expresa la autora: «... esa normalización de la legislación excepcional contraterrorista hace que sea preocupante la deriva que el estado de derecho puede estar tomando a raíz de la aplicación ordinaria de medidas que proceden de dicha legislación». Este fenómeno de normalización de la emergencia, que ha resultado escandalosamente aplicado en EEUU y en Inglaterra, halla también reflejo en el caso francés que lo formaliza en 2017 en el mismo momento en que, derogando la normativa de urgencia, traslada sus principales contenidos a la ley $1510 / 17$ que, no en vano, entra en vigor el mismo día de la derogación de la emergencia.

3.- Según se ha dicho ya, el trabajo de la profesora SERRA aparece en un 
momento francamente especial, en España y en el resto del mundo. En efecto, en plena vivencia de los efectos de la actual pandemia la lectura del libro adquiere si cabe mayor interés por cuanto su discurso gira en torno a los poderes excepcionales de los órganos estatales y en especial del ejecutivo. La actualidad de la presente vivencia de tantos limites a nuestros derechos derivados de la situación de pandemia nos permite tomar con mayor interés la lectura que nos pone frente al desequilibrio de los poderes (y por consiguiente de las modificaciones a que puede estar llevando la situación de emergencia en la forma de gobierno) y si se me apura que también cabe observar indeseables cambios en la forma de estado que va sufriendo cierta minusvaloración de sus grandes principios democráticos.

$Y$ todo ello en un libro que se planificó, desarrolló y «cerró» en vísperas de esta nueva e inesperada emergencia global. Las reflexiones que en él se contienen han de resultar útiles también para la inesperada situación sobrevenda y sitúa a la autora en el punto de partida para seguir reflexionando sobre el problema central que se ha hecho hoy más vivo que nunca. Así, cuando formula el balance del problema invocando, también, la responsabilidad social en el logro de la seguridad: «seguir las tradicionales reglas de legalidad, finalidad y proporcionalidad, y estar acompañado de las garantías adecuadas» (pag. 173).

Personalmente, me resulta inevitable el recuerdo de mi planteamiento en torno al diferente régimen jurídico de las libertades públicas respecto de los que podemos llamar derechos personales o más bien personalísimos a los que indirectamente he aludido supra citando la «ordenación sistemática». Es cierto que la autora, como en general quienes estudian la legislación antiterrorista destacan sus efectos invasivos en la privacy y en cuanto supone que del tratamiento de datos pueden obtener elementos de nuestra personalidad quienes lo llevan a cabo. Pero no lo es menos que, puestos a analizar los concretos derechos más afectados en su libre ejercicio también los autores suelen centrarse en las llamadas libertades públicas. Así lo hace la autora después de ocuparse de los problemas que estas situaciones excepcionales generan en la privacidad. En efecto, en p. 101 y ss se ocupa del chilling effect como efecto inhibidor del libre comportamiento que tiene en la gente el saber que el Estado la somete a vigilancia con el masivo tratamiento de datos de que dispone al haberlos controlado y reunido a partir del pretexto (o razón) de la lucha antiterrorista. Ello tiene efectos principalmente en la privacidad, pero también en la libertad de expresión.

4.- En materia de privacidad y datos personales analiza la autora las medidas legislativas adoptadas por los países de nuestro entorno con ocasión de disponer de medidas preventivas o proactivas en la lucha terrorista observando en general que, si bien se exige la cobertura legal y el respeto a las garantías que también han de determinarse por ley, no cabe ignorar las excepciones que se han ido introduciendo en los casos de persecución del terrorismo en los que, aun persistiendo las garantías se flexibilizan de algún modo al dejar en manos del 
ejecutivo la decisión de intervención (claramente en el caso inglés o francés) en situaciones de urgencia o, como en España, pudiendo actuar sin la previa autorización judicial, pero debiendo comunicar al juez todas las actuaciones en 24 horas máximo. Cabe, pues, concluir que la excepcionalidad de la actuación de que se trata no ignora a limine la existencia de garantías y principios de aplicación en todo Estado de Derecho, aun cuando no sean exactamente los de la actividad policial ordinaria. Se detiene en el caso del tratamiento de datos y en particular en el traspaso de los mismos de las compañías suministradoras a los Estados a partir de acuerdos de la UE y de esta con otros estados subrayando, junto a su interés en la lucha contra el terrorismo yijadista, el pronunciamiento del TEDH y del TJUE en defensa de las garantías que se deben tener en cuenta, en particular su rechazo a los acuerdos demasiado abiertos o flexibles en los que se imponen deberes genéricos que no siempre responden a una necesidad concreta.

Pero como ya he advertido no es menor el interés por las libertades públicas y, por ello, se dedica el Capítulo 7 al derecho a informar y recibir información, para a continuación analizar, en los capítulos siguientes, los efectos de estas especiales medidas en la libertad de expresión, religiosa, de reunión y de asociación.

Tras recordar la importancia de la información en democracia, SERRA apunta a la necesidad de respetar los secretos cuando de la seguridad del Estado se trata, con citas de Tribunales que han aceptado su papel incluso frente al derecho a la información de los parlamentarios. Pero, siendo los arcana imperii tradicional excepción del derecho a la información, se subraya en el libro que lo novedoso hoy no es tanto la defensa de los secretos de Estado que los Altos Tribunales llevan a cabo, aun sin ignorar las garantías básicas, sino el cambio experimentado por la ciudadanía en el sentido de que su interés por conocer todo aquello le afecta se ve anestesiado por la búsqueda de la seguridad; más aún, los ciudadanos aceptan de buen grado las limitaciones a su libertad con tal de garantizar un mínimo de seguridad.

No menos decisiva para la vida democrática es la libertad de expresión a la que dedica la autora el Capítulo 8 , con independencia del que previamente dedicó a la libertad de información. Creo que es un acierto que distinga en capítulos diferentes los dos derechos-libertades del art. 20. 1 , a y d CE. Justamente esta distinción le permite analizar los límites que recientemente ha sentado la jurisprudencia y la legislación penal a la libertad de expresión con ocasión de la lucha antiterrorista: esta libertad no puede dar cobertura a la apología del terrorismo y en tal sentido se han adoptado medidas por los distintos países que no siempre respetan los criterios más laxos o permisivos de los tribunales internacionales. Junto a la experiencia en España, destaca la autora el caso de Francia o Austria por su dureza y porque estos dos países han eliminado la garantía judicial en concreto para el cierre y control de los mensajes apologéticos a través de la red. Es justamente esta especial forma 
de difusión que se lleva a cabo a través de la red la que plantea cuestiones jurídicas más difíciles de resolver y, en especial, el papel de los titulares de servicios en red (pp. 166 y ss).

Sin duda, una de las cuestiones jurídicas de mayor complejidad de las que se apuntan en el libro es justamente la derivada de la relación entre los Estados (y los organismos de la UE que van dictando disposiciones a las que se deben ajustar los Estados miembros) y las compañías prestadoras de servicios que, amparadas en su condición privada y en su función de hacer realidad la libertad de expresión, se resisten a llevar a cabo el control de contenidos que los Estados requieren en la lucha contra el terrorismo y su apología. Junto a esta difícil relación jurídica, se plantea la dificultad de la observancia de los contenidos y su calificación por parte de las empresas.

En esta línea de pensamiento me satisface comprobar que la autora, defendiendo la aplicación de los tradicionales principios de las libertades y en particular de la de expresión e información, discrepa de algunas de las medidas más recientes adoptadas y alentadas por la UE en las que se ignora la tradicional garantía de la intervención judicial al promover una especie de «censura privada» que autorizaría a las empresas privadas a calificar de buena o mala información, y por consiguiente a poder eliminar partes de ella, en función de sus criterios y no de los principios generales aludidos que, aunque sean los tradicionales son siempre válidos, a juicio de la autora y de mi misma.
No sé si personalmente hubiera incluido el capítulo de la libertad religiosa que por sus especiales características respecto de la cuestión estudiada le obliga a alejarse del enfoque elegido, que sí se mantiene coherentemente en los restantes. En cambio, en el dedicado a la libertad de reunión y sus posibles limitaciones en atención a medidas o criterios derivados de la lucha antiterrorista, sobre permitirle recuperar el enfoque general, induce de nuevo a encontramos con pensamientos paralelos que nos lleva hasta la actual situación de pandemia. Porque es inevitable la recurrente comparación de situaciones (la estudiada por la autora y la sobrevenida que dio lugar en marzo a la adopción del estado de alarma y a límites y restricciones que van mucho más allá de las previstas constitucionalmente por cuanto muy directamente, aunque en forma implícita, ha afectado a esta libertad de reunión. La autora discurre sobre la dificultad de limitar las reuniones siempre que sean pacíficas pero contemplando la complejidad de calificación cuando en ellas se realiza apología del terrorismo, lo que obviamente, es difícil o imposible determinar a priori en el momento de la comunicación de los convocantes a la autoridad gubernativa.

Siendo clara sin embargo la mención del orden público como límite impuesto por el propio texto constitucional, y en la medida en que la seguridad pública contiene no pocos elementos de aquel, también los actos terroristas han llevado a plantear la defensa de dicha seguridad de las personas como prevención frente a la comisión de actos terroristas en 
supuestos de aglomeraciones ciudadanas; el hecho de que se haya producido en la realidad este tipo de ataques no impide sin embargo que resulte extraordinariamente difícil prohibir $a$ priori las reuniones en términos constitucionales salvo que los indicios del peligro fueran tan claros que no impedirlas o disolverlas constituiría un acto de absoluta irresponsabilidad. Francia ofrece un ejemplo de lo dicho que quedó regulado por la ya citada Ley de 30 de octubre de 2017, aunque el carácter general de la prohibición provocó un pronunciamiento negativo por parte del Conseil Constitutionnel. El pronunciamiento semejante del Comité de derechos humanos del parlamento británico le permite concluir sobre la generalizada limitación de derechos y su aceptación por la ciudadanía ante el riesgo de pérdida de su seguridad.

Las conclusiones a las que llega giran en torno a la preocupación de que prime la seguridad dejando de lado los valores constitucionales. Por tanto, invoca que el legislador de la seguridad pública sea lo más claro posible y se esfuerce en determinar tanto la tipología de las actuaciones como las garantías de que se han de acompañar para evitar los términos vagos, y poder reducir al mínimo las contradicciones en el ejercicio de los controles por los jueces. En síntesis, la mayor regulación posible en la previsión de la seguridad sin que ello permita ignorar los principios de responsabilidad y proporcionalidad que deben presidir toda actuación pública.

Remedio Sánchez Ferriz

Catedrática de Derecho Constitucional Universitat de València 


\title{
Serra Cristobal, Rosario, La seguridad como amenaza. Los de- safios de la lucha contra el terrorismo para el Estado democrá- tico, Tirant lo Blanch. Valencia, 2020, 265 pp. ISBN 978-84- 1336-666-1.
}

\author{
http://dx.doi.org/10.18543/ed-68(2)-2020pp377-383
}

\section{Copyright}

Estudios de Deusto es una revista de acceso abierto, lo que significa que es de libre acceso en su integridad. Se permite su lectura, la búsqueda, descarga, distribución y reutilización legal en cualquier tipo de soporte sólo para fines no comerciales, sin la previa autorización del editor o el autor, siempre que la obra original sea debidamente citada y cualquier cambio en el original esté claramente indicado

Estudios de Deusto is an Open Access journal which means that it is free for full access, reading, search, download, distribution, and lawful reuse in any medium only for non-commercial purposes, without prior permission from the Publisher or the author; provided the original work is properly cited and any changes to the original are clearly indicated. 